\title{
Resource use efficiency of landowners and tenants in cassava based farms in Akwa Ibom State, Nigeria: A comparative analysis.
}

\author{
Ebong, V. $\mathrm{O}^{1}$. ; E. O. Effiong ${ }^{1}$; A. J. Eshiet ${ }^{1}$ and Hope Nuka ${ }^{2}$ \\ ${ }^{1}$ Dept. of Agric. Econs/ Extension, University of Uyo, Akwa Ibom State, Nigeria. \\ ${ }^{2}$ Dept. of Agric. Econs/ Extension, Rivers University of Science \& Technology, Port Harcourt. \\ Rivers State, Nigeria
}

\begin{abstract}
This study investigated the resource use efficiency of landowners and tenants in cassava based farms in Akwa lbom State, Nigeria. Multistage and purposive sampling techniques were employed in selecting 90 cassava farmers from each of the two categories of farmers, making a total of 180 respondents. Stochastic production frontier model was adopted in the analysis. The result revealed that the coefficient of farm size and labour were not only positive but significantly related to the resource use by the landowners while farm size, labour and capital became significant variable to tenants in their use of farm resources. For the inefficiency model, the variation in the level of resource use efficiency was significantly influenced by household head educational level, sex and farming experience. However, education level, household size and farming experience significantly affected the efficiency of resource use in tenants' farms. All the farmers in both farm categories were producing below the maximum efficiency frontier, although tenants' famers tend to be more efficient in their use of resources than their landowners counterpart. Substantial scope exist for improving the efficiency of resource use in both landowners and tenants farms.
\end{abstract}

Keywords: Resource-use efficiency, landowners, tenants, cassava based farms, comparative analysis, Akwa Ibom State, Nigeria.

\section{INTRODUCTION}

Nigerian cassava production is by far the largest in the world; a third more than production in Brazil and almost double the production of Indonesia and Thailand. The Food and Agriculture Organization of the United Nations (FAO) in Rome estimated 2002 cassava production in Nigeria to be approximately 34 million tonnes. The trend for cassava production reported by the Central Bank of Nigeria mirrored the FAO data until 1996 and thereafter rises to the highest estimate of production at 37 million tonnes in 2000 (FMANR, 1997; Central Bank of Nigeria). The third series provided by the PCU (PCU, 2003) had the most conservative estimate of production at 28 million tonnes in 2002. Comparing the output of various crops in Nigeria, cassava production ranks first, followed by yam production at 27 million tonnes in 2002, sorghum at 7 million tonnes, millet at 6 million tonnes and rice at 5 million tones. Akwa lbom, Cross River, Rivers and Delta dominate state cassava production in the South- South of Nigeria with an estimated production figure of $6,268,114$ tonnes in 2000; 6,533,944 tonnes in 2001 and 6,321,674 tonnes in 2002 (FAO,2004).

In Nigeria, cassava is generally believed to be cultivated by small scaled farmers with low resources (Ezebuiro et al, 2008). However, cassava farms just like the other crop farmers are characterized by very low productivity which is a crucial issue in the Nigerian agriculture. The problem of declining crop productivity in Nigeria is important. Despite all human and material resources devoted to agriculture, the productive efficiency for most crops still fall under 60 per cent (FDA, 1995). Farmers' output must therefore be expanded with existing levels of conventional inputs and technology. More than ever, farmers will have to produce more efficiently, that is, producing maximal output from a given mix inputs or use the minimum levels of inputs for a given levels of output.

The problem of Nigerian agriculture revolved around the efficiency with which farmers use resources on their farms. It is concern on how the various resources that explain farm efficiency could be examined so as to improve crop production in Akwa 
Ibom State and hence Nigeria. This scenario therefore calls for the following research questions: How efficient are Nigerian farm firms on resource use? What are the factors that significantly affect farm level resource use? To what extent do these factors improve crop production? This study thus examines the resource use efficiency in Nigeria, using Akwa Ibom State as a case study. It specifically identified and examined the determinants and levels of resource use in cassava - based farms. This study has become necessary since cassava farms being intercropped with other crops (cassava - based farms) are the most popular arable cropping system in the study area.

\section{MATERIALS AND METHODS}

The study Area and Sample: The study was conducted in Akwa Ibom State, Nigeria. It is located in the South-South geopolitical and South-East ecological Zone of Nigeria. Akwa Ibom State is one of the coastal States in the Niger Delta Region and shares a common boundary with Cross River State in the East, Rivers State in the West, Abia State in the North and Atlantic Ocean in the South. It lies between latitude $4^{0} 30^{1}$ and $5^{0} 33^{1}$ North and longitude $7^{0}$ $30^{1}$ and $8^{0} 25^{1}$ East of equator. The State has a population of about 3.92 million people (NPC, 2006).

The State's vegetation consists of mangrove forest in the South coastal area and thick rain forest inland. Seventy per cent of the soil is part of the tertiary coastal plain (Udo, 1994). Akwa Ibom State is blessed with abundant natural and human resources including crude oil, natural gas, mineral resources and a diversity of agricultural crops such as oil palm, cocoa, rubber, plantain, cassava, yam and beans and people with wealth of knowledge.

Source of data and Sample: The study used mainly primary data collected from the sampled cassava farmers in a well structured questionnaire. The State is divided is divided into six agricultural zones by the Akwa Ibom State Agricultural Development Project (AKADEP) based on the geo- ecological and cultural characteristics of the State. Additionally cassava is virtually grown in all the ADP zones in the State. Multi-stage and purposive sampling techniques were employed in the study. First and second stage witness the purposive selection of six (6) Local Government Areas, each from the six ADP zones and then the selection of one Village each from the six LGAs based on the introduction of cassava competitiveness programmes in these areas. The third and the last stage was the selection of the sample cassava farmers from each of the chosen villages using simple random sampling. The sampled farmers included eighteen (18) landowners and eighteen (18) tenant cassava farmers from each of the Villages, thus making a total of 216 respondents, comprising 108 landowners and 108 tenant farmers. However a total of 180 questionnaires were recovered and used for the analysis constituting $83 \%$ of the administered questionnaires.

Analytical Technique: The stochastic frontier production function as proposed by Aigner et al (1977) and was further improved and used by Batteses \& Coeli (1995); Amaza \& Olayemi, (2002); Helfand, (2003); Maurice, (2004) and Ebong et al (2009) was used in analyzing data generated from this Study. This was used to estimate the resource use efficiency of the landowners and tenants in cassava based farms. The model used for the study is specified as follows: $Y=f\left(X_{a}, \ldots \beta\right) e^{\varepsilon} \ldots \ldots \ldots \ldots \ldots(1)$ where $\mathrm{Y}$ is the quantity of output in $\mathrm{kg} ; \mathrm{Xa}$ is the vector of input quantities; $\beta$ is the Vector of parameters and $e$ is the error term. $\varepsilon$ is a stochastic disturbance term consisting of two independent elements $u$ and $v$ as $\varepsilon=u+v \ldots \ldots \ldots \ldots \ldots$ (2)

The technical efficiency of an individual farmer is defined as the ratio of the observed output to the corresponding frontier output, given the available technology. TE $=$ yi/yi ${ }^{*}=\exp . \quad \varepsilon(U / \varepsilon)$ where TE is the technical efficiency for each farm, Yi is the observed output and $\mathrm{yi}^{\star}$ is the frontier output.

The empirical model for this study is assumed to be specified by the Cobb Douglas frontier production function and defined as follows:

$\ln Y=b_{0}+b_{1} \ln X_{1}+b_{2} \ln X_{2}+b_{3} \ln X_{3}+b_{4} \ln X_{4}+$ $\mathrm{b}_{4} \ln \mathrm{X}_{5}+\mathrm{V}-\mathrm{U} \ldots \ldots \ldots \ldots(4)$

Where: $Y=$ Output of Cassava per farm type (kg); X1 $=$ Farm Size ( ha); $X_{2}=$ Planting materials (Cassava stems) in $\mathrm{kg} ; X_{3}=$ Labour (mandays); $x_{4}=$ Capital (N); $X_{5}=$ Quantity of fertilizer $\mathrm{kg}$ ); $b_{0}=$ Intercept; $b_{1}$ $b_{5}=$ Production function parameters to be estimated; $\mathrm{V}=$ Random variability that cannot be influenced by the farmers; $U=$ Deviation from maximum potential output attributed to technical inefficiency.

The technical inefficiency model was also estimated as follows:

$T E=P_{0}+P_{1} Z_{1}+P_{1} Z_{2}+P_{3} Z_{3}+P_{4} Z_{4}+P_{5} Z_{5}+e$ (5)

Where $Z_{1}=$ Farmer's level of formal education (years), $Z_{2}=$ Household size ( Number of household 
members), $Z_{3}=$ Sex of farmers (Dummy: $1=$ male, 0 $=$ female), $Z_{4}=$ Age of farmers (years) $Z_{5}=$ Framing experience (years), $\mathrm{PO}=$ Intercept, $\mathrm{P}_{1}-\mathrm{P}_{5}=$ parameters to be estimated and $\mathrm{e}=$ error term assumed to be randomly and normally distributed.

\section{RESULTS AND DISCUSSION}

The estimation of sigma- squared $\left(\delta^{2}\right)$ in both the landowners and the tenants are significantly at $1 \%$ significant level, indicating a good fit and correctness of the specified distribution assumption of the composite error term. Moreover, the variance ratio (gamma, $Y$ ) is estimated at 0.2275 in the landowners and statistically significant at $1 \%$ while in tenants, it is estimated as low as .00004 but also statistically significant at $1 \%$. This implies that the random component of the inefficiency effect thus makes a significant contribution in the analysis of the cassava production of the sampled farmers. Therefore the result of the diagnostic statistics confirms the relevance of the stochastic parametric production frontier and maximum likelihood estimation.

The estimated coefficients of farm size and labour are all positive and statistically significant at $1 \%$ and $5 \%$, respectively. These observations are in line with the a priori expectation and imply that the output of the landowners in the study area would be expected to increase with the increasing use of such production inputs as farm size and labour. However, in the tenant farms, the coefficient of farm size (0.4889) and labour (0.5494) are also positive and statistically significant at $1 \%$ and $10 \%$ respectively. The implication of this result is that increasing the farm size by $1 \%$ will increase the output of cassava by $48.89 \%$ while $10 \%$ increase in labour supply will increase the cassava output by $54.94 \%$. Amaza \& Olayemi (2000), Amaza et al. (2005), Ebong (2005), Onyenweaku et al. (2005), Bamidele, et al (2008) and Ebong et al (2009) also reported a positive and significant relationship between these variables and technical efficiency in Nigeria. This means that there is still some scope for increasing output per hectare by increasing farm size and labour. Although the coefficient of capital in tenants' farms is negative ($0.9325)$, it is statistically significant at $10 \%$. This means that capital is an important factor for increased cassava output but the inability of the tenants to acquire enough capital leads to a reduction in the level of cassava output. There is therefore some scope for increasing output by increasing capital.
The source of inefficiency is examined for landowners and tenant cassava farms by using the estimated P-coefficient in Table. I associated with the inefficiency variables in equation 5 . The coefficient of farming experience (0.3184) and education level $(0.9875)$ for landowners were estimated to be positives which do not conforms with the a -priori expectations but statistically significant at $5 \%$ and $10 \%$ respectively. This implies that as the farmers in the study area advance in farming experience and education levels, inefficiency in the resource use increases and technical efficiency decreases. The coefficient of sex of farmers was estimated to be negative $(-0.4549)$ and significant at $10 \%$. This conforms to a - priori expectations and indicates that resource use inefficiency of females who have been shown to be actively involved in cassava production decreases with the increase in technical efficiency. This could be due to the fact that females are regarded to be more industrious in the cassava production.

In the tenants' farms, the inefficiency model indicates that the estimated coefficient of education level, household size and farming experience are all significant at $1 \%, 5 \%$ and $5 \%$ respectively but positively related to technical efficiency. This result is against a priori expectation and implies that as the farmers' education level, household size and farming experience increases in the study area, inefficiency in the resource use increases and technical efficiency decreases. However, the only negatively correlated variable remains the farmers' age $(-0.0420)$ which is in line with a- priori expectation but not significant at any level. The implication is that the older farmers are more efficient in cassava production than the younger ones. That is, as the age of the farmers' increases, inefficiency decreases with increase efficiency.

The distribution of farm-specific resource-use efficiency indices among the two farms is shown in table 2. The resource use efficiency of the sampled farmers in both farms is less than one (i.e. 100\%) indicating that all the farmers are producing below the maximum efficiency frontier. The efficiency indices in the landowners' farms range from $0.33-0.97$ with a mean index of 0.71 while in the tenants' farms the efficiency range is $0.10-0.99$ with a mean of 0.90 . The picture that emerges from the analysis is one of generally high resource-use efficiency in cassava production in the study area as most of the farmers (86.67\% of landowners and $88.89 \%$ of tenant farmers) produce above 0.50 efficiency index. 
Table 1: Maximum Likelihood Estimates of the Parameters of the Stochastic Frontier Production Function.

\begin{tabular}{|c|c|c|c|c|c|}
\hline \multirow[b]{2}{*}{ Variables } & \multirow[b]{2}{*}{ Parameters } & \multicolumn{2}{|c|}{ Landowners } & \multicolumn{2}{|c|}{ Tenants } \\
\hline & & Coefficient & T-ratio & Coefficient & T-ratio \\
\hline \multicolumn{6}{|l|}{$\begin{array}{l}\text { Stochastic } \\
\text { Frontier }\end{array}$} \\
\hline Constant & $b_{0}$ & 4.4045 & $4.3968^{* * *}$ & 6.3140 & $5.9280^{* * *}$ \\
\hline Farm size, $\mathrm{X}_{1}$ & $\mathrm{~b}_{1}$ & 1.2328 & $11.8275^{* * *}$ & 0.4889 & $3.4410^{* * *}$ \\
\hline Plant. material, $\mathrm{X}_{2}$ & $b_{2}$ & -0.0829 & -0.6506 & -0.0733 & -07764 \\
\hline Labour, $\mathrm{X}_{3}$ & $b_{3}$ & 0.2607 & $2.1799^{* *}$ & 0.5494 & $1.7006^{*}$ \\
\hline Capital, $\mathrm{X}_{4}$ & $\mathrm{~b}_{4}$ & -0.0395 & -0.5469 & -0.9325 & -1.9203 * \\
\hline Fertilizer, $\mathrm{X}_{5}$ & $b_{5}$ & $-0 . .0293$ & -0.9695 & -0.0349 & -1.1368 \\
\hline \multicolumn{6}{|l|}{ Inefficiency effects } \\
\hline Constant & $p_{o}$ & -3.2515 & -0.8555 & -0.2647 & -0.3098 \\
\hline Education level, $Z_{1}$ & $\mathrm{p}_{1}$ & 0.9875 & 1.7296 * & 0.1004 & $7.0700^{* * *}$ \\
\hline Household size, $Z_{2}$ & $\mathrm{p}_{2}$ & 0.3020 & 0.9297 & 0.2015 & 2.4820 ** \\
\hline Sex of farmer, $Z_{3}$ & $p_{3}$ & -0.4549 & $-1.6750 *$ & 0.1910 & 0.9717 \\
\hline Age of farmer, $Z_{4}$ & $p_{4}$ & 0.0449 & 0.1108 & -0.0420 & -0.1964 \\
\hline $\begin{array}{l}\text { Farmer's } \\
\text { experience, } Z_{5}\end{array}$ & $\mathrm{p}_{5}$ & 0.3184 & 2.002 ** & 0.3134 & $2.040 * *$ \\
\hline \multicolumn{6}{|l|}{$\begin{array}{l}\text { Diagnostic } \\
\text { statistics }\end{array}$} \\
\hline Likelihood ratio test & & -73.0161 & & -58.9356 & \\
\hline $\begin{array}{l}\text { Sigma -sguared } \\
\left(\delta^{2}\right)\end{array}$ & & 0.3301 & $4.7286^{\star * *}$ & 0.2173 & $5.6959 * * *$ \\
\hline Gamma(Y) & & 0.2275 & $1.2772^{*}$ & 0.00004 & $2.9991^{* * *}$ \\
\hline Sample size & & 90 & & 90 & \\
\hline
\end{tabular}

${ }^{* * *}(\mathrm{O}<0.01){ }^{* *}(\mathrm{P}<0.05) *(\mathrm{P}<0.10)$; summarized from computer output $(2010)$

Table 2: Distribution of farm-specific resource-use efficiency indices in both farms.

\begin{tabular}{|c|c|c|c|c|}
\hline \multirow{2}{*}{ Efficiency Index } & \multicolumn{2}{|l|}{ Landowners } & \multicolumn{2}{|c|}{ Tenants } \\
\hline & Freq & $\%$ & Freq. & $\%$ \\
\hline $0.00-0.10$ & 0 & 0.00 & 0 & 0.00 \\
\hline $0.11-0.20$ & 0 & 0.00 & 10 & 11.11 \\
\hline $0.21-0.30$ & 0 & 0.00 & 0 & 0.00 \\
\hline $0.31-0.40$ & 3 & 3.33 & 0 & 0.00 \\
\hline $0.41-0.50$ & 9 & 10.00 & 0 & 0.00 \\
\hline $0.51-0.60$ & 10 & 11.11 & 0 & 0.00 \\
\hline $0.61-0.70$ & 15 & 16.67 & 0 & 0.00 \\
\hline $0.71-0.80$ & 17 & 18.89 & 9 & 10.00 \\
\hline $0.81-0.90$ & 28 & 31.11 & 26 & 28.89 \\
\hline $0.91-1.00$ & 8 & 8.89 & 45 & 50.00 \\
\hline Total & 75 & 100.00 & 90 & 100.00 \\
\hline Mean & \multicolumn{2}{|c|}{0.71} & \multicolumn{2}{|c|}{0.90} \\
\hline Minimum & \multicolumn{2}{|c|}{0.33} & \multicolumn{2}{|c|}{0.10} \\
\hline Maximum & \multicolumn{2}{|c|}{0.97} & \multicolumn{2}{|c|}{0.99} \\
\hline
\end{tabular}

Source: Computed from MLE Result (2010). 
However, $58.89 \%$ of the landowners and $50.00 \%$ of tenants in the study area produce above the estimated average technical efficiency index of 0.71 and 0.90 respectively. The distribution of resourceuse efficiency suggests that potential gain among the sample farmers is not much. Thus, in the short-run, there is a scope of increasing cassava production in the landowner farms by $29 \%$ and in the tenant farms by $10 \%$ by adopting the technology and technique used by the best-practice farmer. The result of this study further confirm the findings from similar studies conducted by Bamidele et al, (2008) and Ebong, (2009) but however deviates from the earlier studies conducted by Ali \& Byerlee (1991), Onyenweaku et al. (2005) and Amaza et al. (2005) which indicated a wide gap between the maximum and the average technically efficient farmer on food crop production. On the whole tenant farmers are more efficient in the use of available farm resources in cassava production than their landowner counterparts.

\section{CONCLUSION:}

This study investigated the resource use efficiency of landowners and tenant farmers in cassava based farms in Akwa Ibom State, Nigeria. The findings of this study clearly established the fact that although landowners and the tenants' farmers in the study area are technically efficient in their use of resources but the tenant farmers are more technically efficient. There is however, substantial scope for improving productivity and output at the existing levels of resources used in both farms. Efforts at reducing labour usage in the cassava based production system should be enhanced. There is also an urgent need to ensure access of the farmers to education, capital, larger farm size plots and above all mobilised them into viable cooperative groups to acquire better production inputs including funds.

\section{REFERENCES}

Aigner D.J., C.A.K. Lovell and P.Schmidt, (1977). Formulation and estimation of stochastic frontier production model. J. Econometrics, 6(1): 21-37

Ali, M. and D. Byerlee, (1991). Economic efficiency of small farmers in a changing world: survey of recent evidence. J. Int. Development , 3:1-27
Amaza, P. S. and J. K. Olayemi, (2002). Analysis of technical inefficiency in food crop production in Gombe State, Nigeria. Applied Economics Letters, 9: 51-54

Amaza, P.S.; P.V. Kwaghe, and N. Ojo, (2005). Determinants of wheat production and technical efficiency in the Chad basin development area, Nigeria. Nigerian J. Agric, Food and Environment, 2:16

Bamidele, F. S; R.O. Babatunde and Ajao Rasheed (2008). "Productivity Analysis of Cassava-based Production Systems in the Guinea Savannah: Case study of Kwara State, Nigeria. American-Eurasian Journal of Scientific Research 3(1): 33 - 39

Battese, G. E. and T. J. Coelli, (1995). A Model for technical inefficiency effect in a stochastic frontier production function for panel data. Empirical Economics, 20: 325-32

Ebong, V.O., 2005. Resource-use efficiency in oil palm production in Akwa Ibom State, Nigeria. South-South J. Culture and Development, 7: 23-38

Ebong, V,O.; U.S, Okoro and E.O. Effiong (2009) "Determinants of Technical Efficiency of Urban Farming in Uyo Metropolis of Akwa Ibom State, Nigeria" International Journal of Agriculture and Social Sciences, 5:89 - 92.

Ezebuiro, N.O; G.O. Chukwo; B.C. Okoye and I. C. Oboagis (2008). Policy Issues and Adoption of Improved Cassava Varieties. Gender Considerations in Umuahia Zone of Abia State. 1056 - 1059

FDA (2005). Federal Department of Agriculture, Federal Ministry of Agriculture Report. Abuja, Nigeria.

Helfand, S. M. (2003). Farm size and determinants of production efficiency in the Brazilian Centre West. Proceedings of the $25^{\text {th }}$ Int. Conf. Agric. Economics, Durban, South Africa. $16^{\text {th }}-22^{\text {nd }}$ August. 605-12.

Maurice, D. C.(2004). Resource Productivity in Cereal Crops Production among Fadama Farmers in Adamawa State, Nigeria. M.Sc. Thesis. Dept, of Agric. Econs/Extension, University of Maiduguri, Nigeria

NPC, (2006). National Population Commission Census Report. Federal Republic of Nigeria Official Gazette, Govt. Press, Abuja

Onyenweaku, C. E; K.C. Igwe, and J.A. Mbanasor (2005). Application of a Stochastic Frontier Production Functions to the measurement of Technical Efficiency in Yam Production in Nasarawa State, Nigeria. J. Sustainable Tropical Agric. Research, 13: 20-25 